\title{
Incentivising contraceptive use: a helping hand or a push in the wrong direction?
}

\author{
Georgeina L Jarman
}

\section{Correspondence to} Georgeina L Jarman, Medical Student, University College London Medical School, London, UK; georgeina.jarman.14@ucl. ac.uk

Received 15 August 2017 Revised 24 August 2017 Accepted 28 August 2017
CrossMark

To cite: Jarman GL. J Fam Plann Reprod Health Care 2017:43:331-334.

\section{INTRODUCTION}

Contraception is essential to allow women control over their bodies and to fulfil their sexual and reproductive health rights. Despite this, in 2014 the World Health Organization (WHO) estimated that 222 million women and adolescent girls were living without modern contraception, mainly affecting vulnerable groups within society. ${ }^{1} \mathrm{~A}$ number of schemes have emerged to address this need for increased contraceptive access in marginalised groups of women. These include incentivising programmes, where a reward is offered in return for use of a contraceptive. Enticing people into any medical intervention invites ethical analysis as the incentive may coerce the individual into a decision that they may not otherwise have made. Coercion threatens informed consent by undermining voluntary decision-making. Thus, using the widely accepted Four Principles of biomedical ethics, beneficence, justice, non-maleficence and autonomy, ${ }^{2}$ I will assess whether two high-incomesetting-based contraceptive incentivising programmes, chosen as examples, could be seen as disregarding the autonomy of the women they are supposedly trying to help.

\section{OUTLINE OF THE TWO SELECTED INCENTIVISING SCHEMES}

The US-based Project Prevention is a non-profit organisation that has garnered much publicity since its founding by Barbara Harris in 1997, following her adoption of four children born to a mother with crack cocaine addiction. The organisation offers a substantial cash incentive (US\$300) to drug-addicted women in return for use of a long-acting reversible contraceptive (LARC) or a sterilisation procedure. ${ }^{3}$ Offering cash incentives to women fuelling a drug habit raises difficult ethical questions: some would claim that this could be looked upon as coercion and a threat to human rights.

On the other side of the Atlantic lies Pause, a UK-based programme that offers support to women who have had children taken into care, and who are at risk of future custodial losses. One of the conditions of entering the programme is for women to use a LARC. In contrast to the cash-in-hand approach of Project Prevention, Pause appears to be a safer alternative, offering women a range of support mechanisms during this 'pause' in their reproductive cycles, to help get their lives back on track. ${ }^{4}$ However, the principle of increasing contraceptive use by the provision of an incentive remains, regardless of its nature. Pause has its own ethical complications too: offering a woman the help she desperately wants and needs, solely under conditions set by the organisation, could be argued as forcing her hand into choosing to use LARC.

\section{BENEFICENCE: FOR THE VULNERABLE WOMAN OR FOR THE SOCIETY SHE STRUGGLES IN?}

Drug and alcohol use in pregnancy can have devastating effects. Children exposed prenatally to drugs and alcohol can face developmental and cognitive delays, behavioural disorders, ${ }^{5}$ and are likely to be taken into care. Project Prevention emphasises this in its literature. ${ }^{3}$ How society can tackle this issue is a complex question, given that the fetus has no rights before birth. Project Prevention's proposal of preventing the woman from becoming pregnant allows her time to seek help for her addiction, while avoiding babies affected by substance misuse being born.

Pause also presents a bleak picture as the driving force behind its work. Within the pilot area, the London Borough of Hackney, they estimated that for 49 
women presenting with chronic social issues, 205 children were removed into care. ${ }^{4}$ Pause prides itself on a dynamic approach, offering individualised programmes to target areas in which women most require support. Many women involved in the programme were in care themselves as children, many have substance abuse issues and the majority are in unsafe domestic environments. ${ }^{4}$ Pause caseworkers remain steadfast in their supporting role, even when women routinely fail to attend appointments; this constant influence in their lives must be a comfort to women previously ostracised and endangered. In this light both projects appear a kind alternative for the vulnerable woman, giving the opportunity to break a vicious cycle and to rehabilitate without fear of becoming pregnant.

But a question that should be asked when considering the beneficence of these schemes is whom the organisation is helping most - the woman, or society? Project Prevention outlines four objectives for its work, in the following order ${ }^{3}$ :

1. Raising public awareness of the effects of drugs/alcohol on the fetus

2. Reducing taxpayer cost

3. Reducing social worker caseloads

4. Removing the burden on clients of having children taken into care.

These objectives suggest that Project Prevention's focus is relieving the weight placed on society by substance abuse, rather than helping individual women. Furthermore, it is possible that the financial incentive is used to fuel drug habits, and that not all women passing through Project Prevention will enter rehabilitation programmes. Although Pause also highlights societal cost, it demonstrates how intervening helps the woman to rehabilitate, alongside saving society money. Beneficence, by definition, places the individual's welfare at the centre of a scheme. On balance, Project Prevention's work, although ostensibly in the interests of the addicted woman, appears to focus more on the benefits to society.

\section{JUSTICE: A HUMAN RIGHTS APPROACH}

The United Nations Population Fund (UNFPA) report of 2012 defined family planning interventions as a right for women, ${ }^{6}$ implying that access to contraception should be universally obtainable. Yet with contraception uptake and availability lowest among those most vulnerable in society, ${ }^{1}$ this right is not currently being satisfied collectively. Failure to fulfil this right can result in unintended pregnancy, which can deprive women of other human rights with devastating effect. For example, unintended adolescent pregnancy can cause women to drop out of education, to which they have a right, to care for the child, worsening the poverty and discrimination that they endure. ${ }^{6}$ Thus, increasing uptake of contraception by providing incentives could help fulfil several human rights for marginalised women, in addition to fulfilling their right to family planning.
In declaring access to family planning to be a right, the UN also included one key word: voluntary. Does the use of incentives undermine this?

Project Prevention works solely with people suffering with substance addiction. In Pause's pilot scheme, 98\% of participating women abused drugs and/or alcohol. ${ }^{4}$ Impulsive, reward-seeking behavioural trends can precede addiction, making dependence more likely to manifest in certain individuals. ${ }^{7}$ Regardless of whether impulsivity is heightened by, or is a predisposing factor to, addiction, it may increase the likelihood of a person accepting a financial incentive by enabling more of the addictive substance to be purchased. In this light, financially incentivising contraceptive use may not be branded 'voluntary', but as a bribe that could be used to fund addiction. This could further repudiate a woman's human rights, by denying her the right to freedom and liberty and to her own thoughts and beliefs, enticing her into a decision that suits the organisation rather than the woman herself.

While Pause offers no money, its incentive of dedicated support could be construed as being emotionally greater than the financial incentive of Project Prevention. Women may aim to regain custody of their children; for some this incentive may surpass any monetary value. Pause tries to combat this, specifying they will not assist with any endeavour to regain custody of children, or to assess parenting ability. ${ }^{4}$ However, the incentive remains, and with $51 \%$ of women in the pilot scheme homeless, ${ }^{4}$ the prospect of committed support could force a decision to take LARC, when without the incentive, the woman may not have voluntarily done so. Although the charity helps to fulfil contraceptive rights, incentivising healthcare may defy other human rights such as the freedom to live and make one's own decisions without influence.

\section{NON-MALEFICENCE: MORE HARM THAN GOOD?}

The difficult social situations faced by women working with Pause include street sex work, criminal proceedings, and domestic violence, ${ }^{4}$ which are all potentially unsafe circumstances for pregnant women. Delaying pregnancy until they are in a safer setting could be in the best interests for such women. Can we defend the use of potentially coercive incentives for this reason? Quite possibly. John Stuart Mill's Harm Principle suggests the prevention of harm to others as the only circumstance in which using power over another against their will could be justified ${ }^{8}$ and this might be applied to incentivising contraception use today, to protect the vulnerable woman. Project Prevention implies this principle in its work; presenting the incentive as a kind preventative measure compared with the lifelong harm that substance abuse in pregnancy can force upon affected children.

Pause's intervention may not directly cause physical harm, but it does have potential to cause distress in the future. Women may feel that they were persuaded 
into a decision by the emotional value of the incentive, and as such may feel in hindsight that they had been manipulated. Furthermore, although Pause clearly states that it will not assist attempts to regain custody, women may feel they have failed if despite getting their lives back on track through Pause, they did not manage to secure custody of their children, and this could negatively impact on their well-being.

Although Pause only offers reversible contraceptive methods, Project Prevention also pays women to undergo sterilisation. Sterilisation in young women is controversial, with studies suggesting young childless women who undergo the procedure are likely to regret their decision. ${ }^{9}$ Of the 5592 clients that had passed through Project Prevention by April 2016, 1828 had undergone tubal ligation in exchange for cash. ${ }^{3}$ Offering large monetary sums to women funding a drug habit in exchange for a permanent medical procedure could be construed as morally dubious; in the future should the woman rehabilitate and wish to start a family, this will not be possible.

\section{AUTONOMY: CHOICE OR COERCION?}

It could be argued that incentivising contraceptive use in marginalised groups of women would allow greater freedom of choice surrounding contraception. However, for women with drug addiction facing the prospect of going through withdrawal because of lack of funds, an offer of $\$ 300$, as in Project Prevention, is surely an offer that some cannot afford to refuse. The response to the offer may become involuntary, undermining autonomous decision-making and negating the validity of the signed consent form.

Coercion by financial incentive is not the only concern for autonomy that rewarding contraceptive use raises. Both organisations discussed here target vulnerable groups of women, with Pause including those with learning difficulties and chronic mental health problems, ${ }^{4}$ whose contraceptive needs should not be overlooked by healthcare professionals. Aside from assessing capacity to make self-healthcare decisions, to ensure understanding of a scheme there should be an educational exercise to minimise coercion. ${ }^{10}$ Although Pause mandates this, Project Prevention does not publicise any such educational intervention, instead stating "if you cannot trust someone with their reproductive choices, how can you trust them with a child?" as a supposedly obvious argument for their incentive. In addition, Project Prevention lacks mandatory channels for offering help to women who do not wish to accept LARC or sterilisation. In the UK, this should be discussed in the contraceptive consultation, but as Project Prevention spreads, for example, into rural communities in Africa, this may not be guaranteed.

\section{CONCLUSION}

I find incentivising contraceptive use in marginalised groups of women a difficult ethical issue to wrestle with. On the one hand, incentives increase contraception uptake and help fulfil reproductive health rights for women who previously may not have had their needs addressed. Conversely, by specifically targeting vulnerable women, the use of a desirable incentive could be seen as coercive. Pause delivers dynamic support, offers no permanent contraceptive procedures, and no money changes hands. This combination of factors reduces the chance of manipulation into the scheme and lessens the risk of the woman regretting her decision in the future. I can understand the publicity that Project Prevention has attracted. Its cash incentive is substantial, referrals to rehabilitation centres are not mandatory, and it does not publicise an educational intervention to ensure women understand their consent to a possibly permanent medical procedure. Besides avoiding the trauma of having a child removed, I question how the scheme helps the women at all.

I conclude that the nature of the incentive is key to determining if it can be ethically justified. Pause's approach to supporting women in association with contraceptive intervention is in my view a far more acceptable solution than the large cash incentive offered by Project Prevention, which I believe is ethically questionable for its accompanying coercive properties.

\section{Collaborators None.}

\section{Competing interests None declared.}

Provenance and peer review Not commissioned; internally peer reviewed.

Author note This is an edited version of the author's original prize-winning entry for the Faculty of Sexual and Reproductive Healthcare's 2017 Margaret Jackson Essay Prize for undergraduate medical students.

(C) Faculty of Sexual and Reproductive Healthcare of the Royal College of Obstetricians and Gynaecologists (unless otherwise stated in the text of the article) 2017. All rights reserved. No commercial use is permitted unless otherwise expressly granted.

\section{REFERENCES}

1 World Health Organization. Ensuring Human Rights Within Contraceptive Programmes: A Human Rights Analysis of Existing Quantitative Indicators. 2014 http://apps.who.int/iris/ bitstream/10665/126799/1/9789241507493_eng.pdf?ua=1\& ua $=1$ (accessed 17 December 2016).

2 Beauchamp TL, Childress JF. Principles of Biomedical Ethics. 7th edn. Oxford, UK: Oxford University Press, 2013.

3 Project Prevention. Letter from destiny. http://www. projectprevention.org/ (accessed 17 December 2016).

4 Pause. http://www.pause.org.uk/ (accessed 17 December 2016).

5 Behnke M, Smith VC. Committee on Fetus and Newborn. Prenatal substance abuse: short- and long-term effects on the exposed fetus. Pediatrics 2013;131:e1009-e1024.

6 United Nations Population Fund (UNFPA). State of the World Population 2012, By Choice, Not By Chance: Family Planning, Human Rights and Development. 2012 http://www.unfpa.org/sites/default/files/resource-pdf/ENSWOP2012-Summary.pdf (accessed 17 Dec 2016). 
7 Grant JE, Chamberlain SR. Impulsive action and impulsive choice across substance and behavioral addictions: cause or consequence? Addict Behav 2014;39:1632-9.

8 Upshur RE. Principles for the justification of public health intervention. Can J Public Health 2002;93:101-3.
9 Benn P, Lupton M. Sterilisation of young, competent, and childless adults. BMJ 2005;330:1323-5.

10 Won T, Blumenthal-Barby J, Chacko M. Paid protection? Ethics of incentivised long-acting reversible contraception in adolescents with alcohol and other drug use. J Med Ethics 2017;43:182-7.

\section{Updated FSRH guideline: Contraception for Women Aged Over 40 Years - what has changed in 2017?}

The sexual and reproductive health (SRH) needs of women aged over 40 years require a special focus. Despite a natural decline in fertility, statistics show a conception rate of 15.1 per 1000 women, ${ }^{1}$ and over $25 \%$ of these conceptions result in abortion. ${ }^{2}$ Therefore, contraception remains important for this group.

This updated 2017 guideline ${ }^{3}$ considers the woman holistically, bearing in mind the reproductive transition she is encountering. While maintaining the focus on the initiation and continued use of contraception, it also considers the woman's contraceptive needs in the context of menopause and hormone replacement therapy (HRT), gynaecology and sexual health.

In the 2017 guideline, $^{3}$ the use of combined hormonal contraception and the progestogen-only injectable in women over 50 is discouraged due to the potential risks to cardiovascular and bone health, respectively. The guideline supports the use of progestogen-only pills, subdermal implants and intrauterine systems as safe alternatives until natural sterility is assumed.

The 2017 guideline ${ }^{3}$ advises that natural loss of fertility may be assumed at 55 years and therefore contraception can be stopped at this age.

In line with NICE guidance, ${ }^{4}$ the use of follicle-stimulating hormone (FSH) levels as a routine tool for diagnosing menopause is discouraged, with greater emphasis being made on managing the symptoms of menopause. The guidance reminds clinicians that contraception should be considered alongside HRT in women who are still at risk of pregnancy.

Women over 40 may use contraception for its non-contraceptive benefits such as managing perimenopausal and/ or menstrual symptoms. Women over 40 have an increased background risk of cardiovascular disease, obesity and breast/gynaecological cancers, which may influence the suitability and safety of particular methods.

While many women over 40 may consider themselves inherently 'low risk' for acquiring sexually transmitted infections (STIS), data demonstrate a continual rise in STI diagnoses in this group, ${ }^{5}$ hence clinicians are reminded to discuss condom use as protection against STIS, even when contraception is no longer required.

\section{Jenine Bignall}

Specialist Registrar Community Sexual \& Reproductive Health, Central and North West London NHS Foundation Trust, Margaret Pyke Centres; London, UK; j.bignall@nhs.net

Provenance and peer review Commissioned; internally peer reviewed.

\section{References}

1 Office for National Statistics. Conceptions in England and Wales: 2015. https://www.ons.gov.uk/peoplepopulationandcommunity/birthsdeathsandmarriages/conceptionandfertilityrates/bulletins/conceptionstatistics/2015 [accessed 5 September 2017].

2 Department of Health. Report on Abortion Statistics in England and Wales for 2016. https://www.gov.uk/government/ statistics/report-on-abortion-statistics-in-england-and-wales-for-2016 [accessed 5 September 2017].

3 Faculty of Sexual \& Reproductive Healthcare. Contraception for Women Aged Over 40 Years. 2017. http://www.fsrh.org/standards-and-guidance/documents/fsrh-guidance-contraception-for-women-aged-over-40-years-2017/ [accessed 5 September 2017].

4 National Institute for Health and Care Excellence. Menopause: Diagnosis and Management. 2015. https://www.nice.org.uk/ guidance/ng23 [accessed 5 September 2017].

5 Public Health England. Sexually Transmitted Infections (STIS): Annual Data Tables. Table 2: New STI diagnoses and rates by gender, sexual risk and age group, 2012 to 2016. https://www.gov.uk/government/statistics/sexually-transmitted-infections-stisannual-data-tables [accessed 5 September 2017]. 